\title{
CERN considers chasing up hints of Higgs boson
}

Alison Abbott, Geneva

Physicists at the European Laboratory for Particle Physics (CERN) in Geneva were locked in a dilemma earlier this week: whether to gamble SFr30 million (US $\$ 17$ million) following up results that could represent the first viewing of CERN's current holy grail, the elusive particle known as Higgs boson.

The data come from four different experiments done over the past six months using CERN's Large Electron-Positron (LEP) collider. But the LEP is scheduled to be switched off at the end of this month to allow construction of the Large Hadron Collider (LHC).

Keeping the LEP online would delay the LHC, possibly until 2006. This could give US scientists at Fermilab's Tevatron proton-antiproton collider time to pip CERN physicists at the post - particularly if the preliminary results provide a strong clue about the energy range to concentrate on.

Due to come online in 2005, the LHC will operate at energy levels of up to $14 \times 10^{12}$ electron volts - high enough to detect the
Higgs boson with certainty, if it exists.

"A number of events have been observed in LEP experiments that are consistent with the production of the Higgs boson, in combination with the $\mathrm{Z}$ boson," says Roger Cashmore, CERN's director of research. But he points out: "Background processes throw up similar events, so more data will be needed to decide whether they are real."

The bulk of the data were collected at between $206 \times 10^{9}$ and $207 \times 10^{9}$ electron volts, the highest energy at which LEP operates stably. The results gathered so far must be compelling enough to persuade CERN's research board that two more months of experiments would "turn the indications into a recognizable real discovery that would be accepted by the scientific community".

"We don't want to be the scientists who go down in history as having missed Higgs," says Tiziano Camporesi, head of CERN's DELPHI experiment, who is convinced that there is a strong case for taking the gamble. A firm decision was due on Tuesday evening (see Nature's website for latest details)

http://www.nature.com

\section{news in brief}

\section{Treatment of accused physicist distresses US academies}

Washington The presidents of the US National Academy of Sciences, the National Academy of Engineering and the Institute of Medicine last week wrote to US Attorney General Janet Reno criticizing the government's treatment of Wen Ho Lee, the Taiwan-born physicist accused of stealing nuclear weapons secrets from Los Alamos National Laboratory.

Although Lee admits downloading information from Los Alamos computers, the presidents say that they are "distressed" over possible human rights violations. "We are concerned that inaccurate and detrimental testimony by government officials resulted in Dr Lee needlessly spending eight months in prison under harsh and questionable conditions of confinement," the presidents wrote.

\section{UK universities must meet postgraduate standards \\ London A far-reaching review of UK university research says that universities will have to meet minimum standards for postgraduate}


training if they are to receive funding. The report, by the Higher Education Funding Council for England, also says that some of the public money that it allocates to universities will go towards helping institutions meet strategic local, regional and national needs.

The report endorses the current system of giving institutions core support on the basis of excellence. But it says that the research assessment exercise used to determine this allocation should be revised to recognize "greater diversity in the characteristics of research excellence".

\section{Lizard fossil returns to US museum}

San Diego A fossil of a gliding lizard from the late Triassic is going from the auction room back to the American Museum of Natural History in New York. A California businessman, Dick Spight, bought Icarosaurus siefkeri at an auction in San Francisco last week for $\$ 167,500$, and promptly announced he would give it to the museum.

The 200-million-year-old specimen was found in a New Jersey quarry in 1960, given to the museum for identification, and reclaimed a decade ago by Alfred Siefker, one of its discoverers. In a move that upset many palaeontologists, Siefker recently put it up for auction, reportedly to pay medical bills.

\section{Germans unearth hoard of} Neanderthal remains

Munich An archaeological gold-mine has been uncovered at a site near Düsseldorf where the original Neanderthal man was discovered in 1856. German archaeologists say they have found three dozen fragments of bones in two caves near the Düssel river. Many are from the original Neanderthal man, including a piece of bone that had been missing from his skull.

They believe that the other bone fragments come from a second skeleton, around 44,000 years old, and suggest that this could represent one of the oldest examples of anatomically modern man. The find, announced last week, also includes thousands of stone tools and chips from tool production from Neanderthal

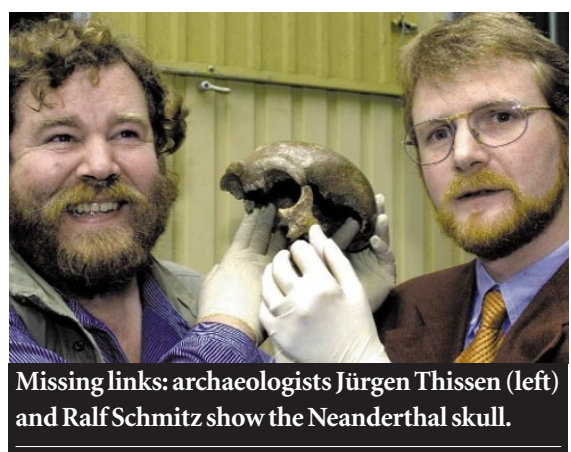

(50,000-40,000 years ago) and Cro-Magnon (around 30,000 years ago) times.

Also found at the site were burnt and cut bones of non-cave-dwelling animals. The archaeologists believe this is evidence of food preparation and cooking, indicating that the Neanderthals belonged to a settlement.

The original Neanderthal site had been located in a working quarry, but its coordinates were lost almost immediately after the skeleton was removed, and was only rediscovered in 1997.

\section{Multidisciplined head appointed at CNRS}

Paris Europe's largest basic research agency, France's Centre National de la Recherche Scientifique (CNRS), has a new directorgeneral, Geneviève Berger. She replaces Catherine Bréchignac, the first woman head of the CNRS, whose mandate ended in July.

Whereas Bréchignac, like most past heads of the CNRS, was a physicist, Berger has taken an interdisciplinary path — she did a $\mathrm{PhD}$ in physics, and has worked in biology, nuclear medicine and imaging. Her laboratory produced the first commercial ultrasound bone imager, used to monitor osteoporosis. Berger comes from the science ministry, where she has been director of the technology department since January. 